\title{
THE USE OF MUSCLE GRAFTS IN MASTOID OPERATIONS.
}

\author{
BY HAROLD KISCH, M.B., B.S., F.R.C.S. \\ Senior Surgeon, Central London, Throat, Nose and Ear Hospital ; Surgeon, Nose, Throat and Ear \\ Department, University College Hospital.
}

THE treatment of the cavity left in the mastoid bone by operation has been a problem which has faced aurists for many years. Simple drainage, blood-clot, skin grafting, periosteal, and fat implantations have all been tried with more or less success. Some years ago I suggested the use of a graft of muscle swung down from the temporal muscle, and left attached in front. This has given me, in a large series of cases, better results than any of the other methods I have used. It is important, however, if the method is to give good results, that the graft be cut and mobilised completely, so that it lies absolutely flaccid in the bony cavity. I propose therefore to describe the method of cutting the graft, and then to indicate the types of cases in which it can be used.

After the mastoid operation has been completed, the cavity is cleansed with hydrogen peroxide, and a small strip of iodoform or B.I.P. gauze is placed in the external auditory meatus so as to replace this in its normal position,

Description of Cutting

the Muscle Graft. should it have been detached during the operation. When this has been done, the size of the cavity, which necessarily varies in different cases, can be accurately gauged and the size of the required piece of muscle estimated. With two retractors, the edge of the skin over the temporal muscle is raised, and with a few touches of a scalpel the temporal muscle is exposed. By tenting the skin with the retractors, the muscle is exposed without making any further incision in the skin. The muscle is then separated freely from the bone with an elevator Anteriorly a vertical incision is then made through the temporal fascia, but not through the muscle. From the upper end of this incision another is carried straight backwards and then downwards, but this incision divides both the fascia and muscle. A tongue of temporal muscle is thus formed, separated above and behind but attached anteriorly. This division is effected by holding the tongue with a pair of forceps and then nicking with the point of the scalpel the intermuscular asepta which are present. At the same time, a gentle pull on the tongue tears some of the muscular fibres and allows the flap to come down. This process is repeated until the flap lies completely flaccid in the cavity, with no tendency to move upwards even when the ear is replaced in the normal position. It will be found that although a certain amount of fibres are separated, a good connection is always left to the main mass of muscle. All this can frequently be done quite bloodlessly but, occasionally, small vessels require twisting or tying. It is necessary that all bleeding be stopped before the incision be closed, as otherwise a hæmatoma may form. The skin incision is then closed and a firm pad placed over the denuded bone area so as to prevent any oozing. No drainage is required, and the only subsequent dressing is the changing of the plug in the meatus, and the cleansing of the middle ear by drops.

(I) To fill the cavity after a radical mastoid operation. In these cases the meatus is detached and pushed forward. The bridge and incus are removed.

Types of Cases in which the Graft can be Used. Usually the malleus and remains of the membrane are left. Any polypi or granulations are removed. No plastic operation on the meatus is required and it is replaced as described above.

(2) To fill the cavity left after an operation for acute mastoiditis has been performed. The graft should never be inserted at the time of the acute operation but at a subsequent one. It is usually undertaken about a fortnight after the acute operation.

(3) To fill the cavity left after a simple mastoid operation performed in cases of chronic mastoiditis in children. In these cases it is usually unnecessary to remove the bridge and incus.

(4) To obtain healing of a mastoid fistula. The fistula is dissected out, and the 
bony cavity cleaned. The graft is then inserted. The edges of the skin incisions are then freshened and sutured.

(5) To stop hæmorrhage from an injured lateral sinus. The graft, here, is used instead of the usual iodoform plug.

\section{CASE OF HYDROCELE OF FEMORAL HERNIAL SAC.}

WOMAN, aged 47 .

BY T. MEYRICK THOMAS, M.CH., F.R.c.s.

Two years' history of lump, right groin, getting gradually larger and recently painful.

Past History.-Previous operation for cure of right inguinal hernia.

Examination showed an oval, soft, fluctuating, translucent, irreducible swelling, $\mathrm{I}_{2} \frac{1}{2}$ in. by $\mathrm{I}$ in., in the right groin, lying for the most part below Poupart's ligament, but overlying it to a slight extent and to the outer side of the pubic spine.

There was a slight impulse on coughing.

Most of the candidates diagnosed femoral hernia, but considered it to be an irreducible epiplocele, whereas the soft cystic feel and translucency should have indicated the true nature of the condition.

One or two candidates, recognizing the fluid consistency of the swelling, made the diagnosis of cyst of the canal of Nuck. This cundition should have been excluded by the situation of the swelling, particularly its relation to the pubic spine. The treatment advocated was in practically every instance correct-radical cure by the "high" operation (via the inguinal route), and suturing conjoined tendon to Astley Cooper's ligament.

This operation was carried out a few days after the demonstration and the diagnosis confirmed.

\section{COMMENTS ON A CASE OF MULTIPLE CHRONIC INFLAMMATORY TUMOURS.}

BY HERMON TAYLOR, M.CH., F.R.c.s.

THIS case which I showed at the Fellowship of Medicine provided a good exercise in History. examination procedure from the candidate's point of view. The case was that of a man, aged 54, who had his first illness in 1927 , which consisted of an attack of painless hæmaturia. Following this, he had hæmaturia occasionally until June, 1930, when he was investigated in St. Thomas's Hospital. He was found to have multiple papillomata of the bladder. These were removed by suprapubic cystostomy.

He was subsequently followed-up for four months, after which he was lost sight of until November, I93I, when a further bout of severe hæmaturia brought him back to hospital, and a second suprapubic cystostomy revealed a totally inoperable and extensive carcinoma of the bladder.

While convalescing from the operation, he had a severe chest complication, which confined him to bed in hospital for fourteen weeks, after which time he was discharged and put on the waiting list for deep X-ray therapy.

Five months ago, in January, 1932, while he was still convalescing, he noticed swellings gradually increasing in size on the right knee and left elbow.

Five weeks ago another swelling developed on his right shin, and he began to get pain in the right hip. He was, however, much stronger than he had been, and had put on $3 \frac{1}{2}$ st. in weight since his last operation.

I first saw him on account of the swellings, which were getting bigger. 